\title{
A TEORIA DAS REPRESENTAÇÕES SOCIAIS: BASES TEÓRICAS E APLICAÇÕES NA EDUCAÇÃO
}

\section{THE THEORY OF SOCIAL REPRESENTATIONS: THEORETICAL BASES AND APPLICATIONS TO EDUCATION}

\author{
Marcela da Conceição Costa ${ }^{1}$ \\ Josemare Pereira dos Santos Pinheiro²
}

\begin{abstract}
Fruto de uma pesquisa de natureza qualitativa, cuja metodologia de procedimento foi classificada como descritivointerpretativa, este trabalho apresentou como objetivo compreender a Teoria da Representação Social e sua importância para os estudos no âmbito educacional, através de uma revisão de literatura. A partir do estudo, constatou-se que a Teoria das Representações Sociais pode ser entendida em termos de processo, perpassando pela objetivação e a ancoragem, e como produto, investigando o núcleo central e os periféricos das representações. Essa última abordagem, proposta por Abric (1994 apud CRUSOÉ, 2009), permeia um crescente contingente de estudos na área da educação à luz da Teoria das Representações Sociais, que em geral trazem no cerne a relação entre as representações sociais dos agentes educativos e as práticas pedagógicas.
\end{abstract}

Palavras-chave: Teoria das Representações Sociais. Práticas Pedagógicas. Pesquisa Educacional.

The objective of this study was to understand the Social Representation Theory and its importance in the educational field through a literature review. It was observed that the Theory of Social Representations can be understood in terms of process, pervading objectification and anchorage, and as a product, investigating the central nucleus and peripherals of the representations. This last approach, proposed by Abric (1994, apud CROSOÉ, 2009), permeates a growing number of studies in the area of education based on the Theory of Social Representations, which usually bring at the core the relation between the social representations of educational agents and their pedagogical practices.

Keywords: Theory of Social Representations. Pedagogical Practices. Educational Research.

\footnotetext{
${ }^{\mathrm{a} T}$ Trabalho apresentado no XV Seminário Estudantil de Pesquisa da FAMAM e selecionado pela comissão científica do evento para publicação. ${ }^{1}$ Discente do curso de Licenciatura em Pedagogia da Faculdade Maria Milza, FAMAM, Currículo lattes: http://lattes.cnpq.br/9430521490308853, Email: marcellacosta01@hotmail.

${ }^{2}$ Doutora em Planejamento Territorial e Desenvolvimento Social (Universidade Católica de Salvador), professora da Universidade Estadual da Bahia e da Faculdade Maria Milza, FAMAM. Currículo lattes: http://lattes.cnpq.br/1636232300151342,Email: pinheiro_neta@yahoo.com.br
} 


\section{INTRODUÇÃO}

O estudo de representações sociais permite compreender a origem dos sistemas de pensamento, bem como a gênese de diferentes comportamentos em contextos variados, uma vez que elas constroem a visão de mundo do sujeito e regem suas atitudes. Neste sentido, a Teoria das Representações Sociais possibilita a reflexão sobre diversos fenômenos apropriados pelo senso comum, em particular questões do âmbito educacional.

Nesse sentido, o artigo objetiva de modo geral compreender a teoria da representação social e sua importância para os estudos na área de Educação, através de uma revisão de literatura. Para tanto, pretende-se apresentar os pressupostos teóricos da Teoria das Representações Sociais e indicar as contribuições deste campo teórico para a pesquisa em Educação.

A pesquisa faz-se relevante por propor uma reflexão a respeito de um campo teórico contemporâneo e interdisciplinar, que admite uma intervenção de fatores sociais e psicológicos nos processos educativos e nos seus resultados. Além de chamar a atenção para a relevância da análise das idéias que se mantêm estáveis no imaginário dos professores, as quais têm origens nas relações cotidianas e servem para a manutenção do sistema educacional, tal como ele é.

Para o alcance do objetivo proposto no artigo, a pesquisa adotou a abordagem qualitativa, por subsidiar a investigação de subjetividades e inferências. Trata-se, quanto aos objetivos, de uma pesquisa descritiva e interpretativa. Para o delineamento da pesquisa, foi feito um levantamento bibliográfico visitando os autores clássicos e atuais que discutem a temática do estudo, entre eles Moscovici (1978), Alves-Mazzotti (2000); Abric (1994 apud CRUSÓE 2009), Jodolet (2011), bem como uma consulta ao Banco de Teses e Dissertações da CAPES, a fim de fazer um breve balanço da produção do conhecimento na área da Educação utilizando a Teoria da Representação Social, em 2017 na Universidade de São Paulo (USP).

\section{ATEORIA DAS REPRESENTAÇÕES SOCIAIS DE SERGE MOSCOVICI}

O estudo pioneiro do sociólogo Durkheim serviu de base para a discussão iniciada por Serge Moscovici em um estudo sobre a psicanálise, inaugurando um campo teórico contraposto à teoria da representação coletiva de Émile Durkheim e à perspectiva individualista da psicologia social da época. De acordo com Alves-Mazzotti (2000), Moscovici considerava a Teoria da Representação Coletiva limitada, pertencente a um grupo genérico de fenômenos psíquicos e sociais, que ignoravam os processos de gênese da diversidade de pensamento e práticas.

O psicólogo social francês apresentou uma proposta de ligação entre pensamento individual e coletivo, evidenciando em seus estudos que a consciência coletiva interfere na construção do pensamento individual e orienta condutas. Moscovici defende que a representação social deve ser vista "tanto na medida em que ela possui uma contextura psicológica autônoma como na medida em que é própria de uma sociedade e uma cultura" (MOSCOVICI, 1978, p.45). Para isso, o teórico investigou como se dá a construção do conhecimento ao mesmo tempo coletivo e individual, situando a relação sujeito e sociedade.

As representações são uma interpretação da realidade, operacionalizada dentro de um contexto. Jodolet (1990, apud ALVES-MAZZZOTTI, 2000) as define como "uma forma especifica de conhecimento, o saber do senso comum, cujos conteúdos manifestam a separação dos processos generativos e funcionais, socialmente marcados. De uma maneira mais ampla designa o pensamento social." Além disso, configuram-se elementos simbólicos, operacionados no sistema psíquico e construídos nas interações com o meio social, que expressam e transformam as relações socias.

Segundo Alves-Mazzotti (2000), as representações sociais tratam da apropriação na consciência individual de significados atribuídos coletivamente, orientando e justificando condutas. Para a autora, os indivíduos expressam suas representações por meio de palavras comuns ao grupo de convivência, 
explicitando opiniões, expectativas e julgamentos sobre determinado objeto.

Assim, entende-se que a função da representação social é interpretar o mundo e ao mesmo tempo conduzir ações. Também tem a finalidade, de acordo com Moscovici (1978), de dar sentido à realidade social, por meio de idéias compartilhadas pelos grupos de sua convivência, guiar comportamentos, uma vez que o conhecimento ancorado no sistema psíquico do sujeito orientará suas práticas, bem como construirá identidade social grupal, considerando que os grupos se diferenciam pelas representações atribuídas aos objetos em diferentes contextos sociais e históricos.

Ao tratar de uma teoria que traz no cerne o conhecimento do senso comum, esbarra-se no descrédito, que em geral, é dado a essa discussão no âmbito acadêmico, desprezando as diversas contribuições desse tipo de saber para compreensão dos fenômenos sociais, principalmente por permitir conhecer a origem de determinados comportamentos em uma sociedade especifica. Segundo Crusoé, (2009, p. 70), esta forma de conhecimento "exprime algumas das "idéias que pairam no ar", que são capazes de revelar o que um determinado grupo pensa sobre uma situação determinada".

A discussão da Teoria das Representações Sociais de acordo com Abric (1994 apud CRUSOÉ, 2009) pode ser compreendida em termos de processo e de produto, pois é ao mesmo tempo produto e processo da inter-relação sujeito e objeto na construção do conhecimento. Sabe-se que a abordagem estrutural proposta por Abric analisa essa teoria em termos de produto, preocupando-se com o conteúdo da representação social, forma e estrutura para investigar o núcleo central e as periferias, que fazem parte da representação do sujeito e regem suas ações.

Como elemento marcante desta abordagem, destaca-se a busca pela relação entre representação social e comportamento. Para demonstrar isso, Abric (1994 apud CRUSOÉ, 2009) procura, por meios de experimentos, evidenciar que o comportamento do sujeito em determinada situação não pode ser compreendido objetivamente, mas pela sua representação daquela situação. Além disso, analisa a estrutura interna da representação, designando o cerne da teoria do núcleo central, que para o teórico indica o significado e organização da representação, conforme afirma Alves Mazzotti (2000).

A idéia essencial de Abric (1994) é a de que toda representação esta organizada em torno de um núcleo central (NC) que determina, ao mesmo tempo, sua significação e sua organização interna. Os outros elementos que entram na composição são chamados de elementos periféricos (EP); eles reconstituem a parte operatória da representação e desempenham um papel essencial no funcionamento e na dinâmica das representações. Sendo mais sensível ás características do contexto imediato, o sistema periférico constitui a interface entre a realidade concreta e o NC.

Neste sentido, Abric tenta evidenciar que a apreensão de uma representação é insuficiente para especificá-la, fazendo-se necessário investigar sua organização em volta do núcleo para identificar as similaridades e divergências entre as representações.

Por outro lado, a abordagem em nível de processo busca compreender como ocorre a incorporação do novo conhecimento no já conhecido, passando por dois processos cognitivos complementares, fundamentais na construção das representações sociais, a objetivação e a ancoragem, propostos por Moscovici (1978).

O primeiro deles consiste em uma operação para tornar familiar o desconhecido. Conforme Jodolet (1990 apud Alves-Mazzotti, 1994), este processo perpassa pela construção seletiva: apropriação de informações seletivamente, guardando apenas as idéias que se aproximam dos conceitos já estabelecidos; a esquematização estruturante: incorporação do conhecimento ao sistema psíquico do sujeito, tornando o abstrato em concreto, produzindo um saber submetido aos saberes existentes; e a naturalização: a representação passa a fazer parte da realidade do individuo.

O segundo processo diz respeito à ancoragem, que se refere ao enraizamento social da representação no sistema de pensamento preexistente. Souza-Santos (2003 apud Oliveira 2011, p. 33) assegura que "O enraizamento de uma representação inscreve-se numa rede de significados articulados e hierarquizados a partir de conhecimentos e valores preexistentes na cultura”. Assume, assim, a função de interpretar a realidade e servir como referência para classificar, comparar objetos desconhecidos mediando à relação do sujeito com as pessoas com as quais convive. 


\section{REFLEXÕES ACERCA DAS CONTRIBUIÇÕES DA TEORIA DAS REPRESENTAÇÕES SOCIAIS PROPOSTAS POR SERGE MOSCOVICI NAPESQUISA EDUCACIONAL}

Segundo Jodolet (2011), os estudos brasileiros no campo teórico em discussão podem ser chamados de "escola brasileira", porém a autora adverte que esta expressão não pode ser confundida com as escolas consagradas que buscam uma abordagem metodológica alternativa, tais como a estruturalista de Abrice e a societal de Doise.

Sobretudo, porque para a autora a expressão significa um conjunto de pesquisadores unidos por uma mesma orientação, que está em torno de problemas verificados na realidade do Brasil. De acordo com Jodolet,

A preocupação dos cientistas não é tanto de tipo puramente teórico, não responde tampouco a um desejo exclusivo de aperfeiçoamento e aprofundamentos de metodologias. A perspectiva comum é de usar a teoria e os modelos de representações sociais para enfrentar questões vivas que atravessam a sociedade brasileira hoje em dia. (JODOLET, 2011, p.4).

Nesse sentido, o estudo de Sá e Arruda (2000), sobre a produção cientifica brasileira no campo das representações socias entre 1988 e 1997, demonstra que a aplicação nas áreas de interface, dá destaque à Educação com $45,3 \%$ dos trabalhos, seguidos da área da Saúde com $28 \%$, Serviço Social $18 \%$, Sociologia $6,9 \%$ e outras áreas, $1,8 \%$.

Os dados apresentados pelos autores mencionados acima apontam que a comunicação das produções nacionais sobre TRS ainda são maiores em eventos e minoria entre publicação de artigos e livros, o que reflete a dificuldade dos pesquisadores brasileiros em realizar trabalhos em nível de publicação. Na área da Educação, eles apontam que os temas mais frequentes abordados sobre a ótica da TRS são trabalho e práticas profissionais e relações educacionais professor-aluno.

Assim, compreende-se que esta perspectiva teórica ofereça importantes alternativas de estudo da realidade educacional, fazendo-se relevante para as pesquisas em Educação que investiguem as relações entre práticas e representações dos sujeitos sociais da escola. Em conformidade, Maia (2001) assegura que,

[...] Durante um certo tempo, o conhecimento popular foi silenciado na escola. Ora, toda sociedade, segundo Moscovici, está permeada por esse conhecimento que ele denominou de representação social. Será que a escola é um espaço de puro de saber científico? Estamos certos que não. O professor e o aluno como atores de uma sociedade em movimento, carregam consigo um saber que se constrói no dia a dia, tanto social, familiar, quanto profissional. E este conhecimento eles trazem para a escola. Identificar elementos desse conhecimento e estabelecer relações com o conhecimento científico, objeto específico de "transmissão" escolar, nos parece ser um importante passo para a compreensão de entraves e desvios que observamos no dia a dia escolar (MAIA, 2001, p. 85).

Entende-se que a construção da representação social significa a acomodação do conhecimento do senso comum nas estruturas mentais, que permitiram aos agentes da escola conservar suas práticas e buscarem os problemas dos seus vícios fora do âmbito escolar.

Referente às representações sociais que permeiam o campo educativo, o estudo de Gilly (2002) aponta a existência de contradições entre as representações de um grupo, em função da submissão a esquemas dominantes, que justificam práticas ao longo da evolução da escola. Principalmente, a partir da expansão do ensino obrigatório na década de 60 , na perspectiva da democratização da escola, em função do crescimento industrial do país, mas embora tenha passado a atender um público maior, mais diverso e ter aumentado os anos de escolarização, não garantiu devidamente o cumprimento da função 
social da escola para todos, dificultando a equalização da educação.

Observa-se, neste período e até hoje, uma contradição marcante na escola: por um lado, é concebida pela maioria como uma ferramenta de equalização social e, por outro lado, nitidamente reproduz as desigualdades sociais dentro da instituição, provocando distorções de rendimento e reprovações.

De acordo com Gilly (2002), em face dessa dicotomia da escola, os diferentes agentes do processo educativo construíram representações para legitimar o funcionamento desigual da escola sem, contudo, negar o seu principio igualitário. Essas representações sociais são apoiadas em "teorias do sujeito", que defendem que a escola é a mesma para todos, sendo explicadas as diferenças de rendimento pelas características individuais, a falta de dom e de talento.

Entretanto, com os avanços das explicações cientificas e do desenvolvimento econômico do país, há uma busca pela ampliação da escola, que amplia o atendimento a classes diversificadas, passa-se a rejeitar a ideologia anterior e surgem outras explicações para a dicotomia da escola, que segundo Gilly (2002), provocarão mudanças no sistema de representação dos envolvidos no sistema educacional. Para a autora citada,

\begin{abstract}
O sistema escolar se transforma sob a pressão de dificuldades econômicas e sociais que fixam os critérios de sua rentabilidade. A representação, sistema simbólico de mediação, segue essas mudanças. Ela traz em si elementos contraditórios dos quais alguns antecipam as evoluções possíveis. Mas foi necessário que o sistema escolar fosse empurrado por determinantes externos para que a construção representativa oficial começasse a oscilar e a se organizar em torno de um novo esquema central, legitimado pelo empréstimo das ciências humanas e sociais, legitimando por sua vez o funcionamento do sistema (Gilly, 2002, p.236).
\end{abstract}

Dessa forma, evidenciam-se as inferências da sociedade sobre a instituição educativa e consequentemente, sobre seus agentes. Sobretudo porque o contexto educacional é formado por sujeitos históricos e sociais; assim, a relação professor aluno é afetada por mecanismos de fora da escola, que interferem no processo educativo, podendo ser compreendidos pelas representações sociais dos educadores que mediam o ato educativo, que por sua vez, possuem bases históricas, sociais, culturais e educacionais, que influenciam sua prática docente.

Além disso, o professor está situado em um grupo de convivência que compartilha diversas representações sociais sobre o fazer pedagógico e os sistemas de aprendizagem, expressando-as também em seu planejamento de ensino e práticas educacionais cotidianas.

Alves-Mazzotti (2000) realizou um levantamento sobre as pesquisas que têm utilizado a teoria da representação social na área da Educação e observou que os professores: i) tendem a atribuir baixas expectativas em relação aos alunos com baixo nível socioeconômico ii) desenvolvem comportamentos diferenciados em relação aos alunos com altas e baixas expectativas, iii) os professores frequentemente associam o fracasso escolar às condições socioeconômicas e psicológicas de seus alunos e seus familiares.

A fim de ampliar a compreensão sobre o estudo das representações sociais na área da Educação, pesquisou-se no Banco de Teses e Dissertações da CAPES, pela seguinte descrição: "Representação social no campo educacional" com o recorte do ano de 2017, delimitando a Educação como grande área e área de concentração. Para refinamento dos dados obtidos, buscou-se a Universidade de São Paulo.

A priori, foram encontrados 44 resultados de busca para teses e 32 para dissertações. Contudo, foram selecionados os trabalhos que indicavam os termos da descrição pesquisados no título. Assim, chegou-se a três teses de doutorado e uma dissertação. Observa-se a seguir, os títulos das referidas pesquisas, 
Quadro1. Teses e Dissertações sobre as representações sociais na Educação.

\begin{tabular}{|l|l|}
\hline TESES & \\
\hline AUTOR & TITULO \\
\hline $\begin{array}{l}\text { Sandra Regina Leite de } \\
\text { Campos }\end{array}$ & $\begin{array}{l}\text { A representação social dos professores de surdos sobre o e nsino de Línguas } \\
\text { e Língua Portuguesa no Ensino Fundamental }\end{array}$ \\
\hline Talita Dias Miranda e Silva & $\begin{array}{l}\text { De pajens a professoras de educação infantil: representações acerca da } \\
\text { carreira e das condições de trabalho no município de São Paulo (1980-2015) }\end{array}$ \\
\hline $\begin{array}{l}\text { Amalia Galvao Idelbrando } \\
\text { Curado }\end{array}$ & Escola pesquisadora: representações e obras \\
\hline DISSERTAÇÃES & $\begin{array}{l}\text { Representaç̃es da atividade docente em uma unidade de ensino de um } \\
\text { Centro Educacional Unificado (CEU) - formas de construção da ação cotidiana }\end{array}$ \\
\hline Ariane Monteiro Siqueira
\end{tabular}

Fonte: Marcela da Conceição Costa, 2018.

Verifica-se que majoritariamente as pesquisas enfocam o trabalho docente, principalmente nas investigações em nível de doutorado, conforme as proposições de Jodolet (2011). Também, foi possível perceber, que em relação aos objetivos propostos nos estudos mencionados anteriormente, há uma tentativa de vincular as representações socias e as práticas dos professores, demonstrando a adoção da Teoria das Representações Sociais em termos de produto, segundo a abordagem estruturalista proposta porAbric (1994, apud CROSUÉ 2009). Como se observa,

Investigar, a partir das perspectivas de professores surdos e ouvintes de sujeitos surdos, as representações sociais do ensino da Língua Brasileira de Sinais (Libras) e Língua Portuguesa do Ensino Fundamental I, na Educação Bilíngue para Surdos, buscando explicitar quanto essas representações interferem na prática docente desses profissionais (CAMPOS, 2017)

Notou-se ainda que os estudos privilegiam na metodologia a abordagem qualitativa, devido talvez à contribuição desta para a investigação de subjetividades. Em relação aos instrumentos de coleta de dados, predominaram o uso de entrevistas e questionários.

De acordo com Nascimenlo-Sehub e Camargo (2000), é relevante a escolha de procedimentos metodológicos diversificados para pesquisa em representações sociais, para dar conta da complexidade deste campo teórico. Duas das pesquisas citadas utilizaram a observação, que é extremamente relevante para estudos que pretendem relacionar as representações sociais dos participantes da pesquisa com suas práticas.

\section{CONSIDERAÇÕES FINAIS}

A Teoria das Representações Sociais tem se constituído como ferramenta fundamental para o entendimento das ocorrências que podem ser observadas na sociedade e que permeiam o imaginário popular. Assim, entende-se que o ato de representar é propriamente humano e também uma forma de interpretar a realidade, a partir do contexto no qual se está inserido. Partindo dessa compreensão, percebe-se que as representações sociais designam o conhecimento do senso comum, que não é o oposto do conhecimento cientifico, mas um saber construído nas relações cotidianas que, por sua vez, orientam condutas.

Nesse sentido, o fazer pedagógico e os agentes do processo educativo não estão indiferentes à prática de representar, tampouco às interferências nas ações. Portanto, a Teoria das Representações Sociais (TRS), proposta por Serge Moscovici, possibilita a compreensão da maneira de pensar dos sujeitos sobre determinadas situações; assim, as pesquisas em Educação à luz da TRS permitem a reflexão sobre diversos fenômenos que circundam o sistema educacional e foram cristalizados pelo senso comum.

Estudar as representações sociais dos sujeitos do sistema educacional é uma oportunidade de 
conhecer as atitudes, comportamentos deste grupo, além da possibilidade de identificar os discursos mais frequentes na realidade educativa, bem como a estrutura que fundamenta a representação.

\section{REFERÊNCIAS}

ABRIC, J.C. L'organisation interne des representations sociales: système central et système périphérique. Em, C. Guimelli (Org.) Structures et Transformations des Representations Sociales. Neuchâtel: Delachaux et Niestlé. 1994.

ALVES-MAZZOTTI, A. J. Representações Socias: aspectos teóricos e aplicações à educação. Em Aberto, Brasília, ano 14, n.61, jan./mar. 2000.

ALVES-MAZZOTTI, A. J. Fracasso Escolar: representações de professores e alunos repetentes. In: Reunião Anual

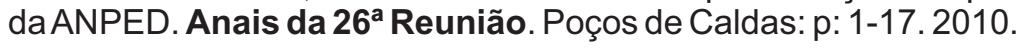

CAMPOS, S. R. LEITE DE. A representação social dos professores de surdos sobre o Ensino de Línguas e Língua Portuguesa no Ensino Fundamental I' 24/03/2017 undefined f. Doutorado em EDUCAÇÃO Instituição de Ensino: UNIVERSIDADE DE SÃO PAULO, São Paulo Biblioteca Depositária: FEUSP

CURADO, A. G. IDELBRANDO. Escola pesquisadora: representações e obras' undefined f. Doutorado em EDUCAÇÃO Instituição de Ensino: UNIVERSIDADE DE SÃO PAULO, São Paulo Biblioteca Depositária: FEUSP, 2017.

CRUSOÉ, N. Margarida de Castro. Interdisciplinaridade: representações sociais de professores de matemática. Natal, RN: Editora da UFRN, 2009.

GILLY, M. As representações sociais no campo educativo. Educar, Editora da UFPR, Curitiba, n. 19, p. 231-252. 2002.

JODOLET, Denise. Ponto de Vista: Sobre o movimento das representações sociais na comunidade científica brasileira. Temas em Psicologia, Vol. 19, no 1, 19-26, 2011.

MAIA, L. S. L.O. que há de concreto no ensino de matemática? Revista ZETETIKÉ. Campinas: CEPMPEM -FE/Unicamp, v. 9, n. 15/16, jan./dez. 2001.

MOSCOVICI, S. A representação social da psicanálise. Tradução de Cabral. Rio de Janeiro: Zahar, 1978.

NASCIMENLO-SEHUB, Clélia M.; CAMARGO, Brigido. V. Psicologia Social. Representações Sociais E Métodos. Temas em Psicologia da SBP, V. B n. J, 281-299, 2000.

OLIVEIRA, T. S. Evangelista de. Representação Social da Repetência. Brasília, Universidade de Brasília-UNB. Monografia, p.96, 2011.

SÁ, C. P. ; ARRUDA, A. O estudo das representações sociais no Brasil. Revista de Ciências Humanas, v.11 n.3, 2000.

SILVA, T. D. MIRANDAE. De pajens a professoras de educação infantil: representações acerca da carreira e das condições de trabalho no município de São Paulo (1980-2015). Doutorado em EDUCAÇÃO Instituição de Ensino: UNIVERSIDADE DE SÃO PAULO, São Paulo Biblioteca Depositária: FEUSP, 2017.

SIQUEIRA, A. MONTEIRO. Representações da atividade docente em uma unidade de ensino de um Centro Educacional Unificado (CEU) - formas de construção da ação cotidiana. Mestrado em EDUCAÇÃO. Faculdade de Educação. USP, 2017. 